\title{
Isolation of 5-Hydroxytryptamine from the Venom of the Indian Red Scorpion (Mesobuthus tamulus)
}

\author{
A.K. Tiwari, M.B. Mandal, S. Kanoo, A.B. Alex, A.C. Jariwala and S.B. Deshpande* \\ Department of Physiology, Institute of Medical Sciences, Banaras Hindu University, Varanasi - 221005, India
}

\begin{abstract}
The present study was undertaken to isolate 5-hydroxytryptamine (5-HT) from crude Indian red scorpion (Mesobuthus tamulus; MBT) venom as it has not been reported yet. Therefore, with the help of bioassay (using gastric fundus contractions) and fluorimetric assay methods, the 5-HT content of crude $M B T$ venom (CV) was determined. The concentration of 5-HT in CV by either of the methods was different (117 times). Further, a 5-HT antagonist methysergide partially blocked the $\mathrm{CV}$-induced gastric fundus contractions. Hence, for isolation and determination of 5-HT in crude $M B T$ venom, CV was subjected to Sephadex gel (G 75-125) filtration chromatography. The eluates were screened for optical density (OD) at $280 \mathrm{~nm}$, lethality and gastric fundus contractions. Two peaks of enhanced gastric fundus contractions were observed between $26-70 \mathrm{ml}$ and $90-110 \mathrm{ml}$ of eluate volumes. As the first peak (between 26-70 ml) eluates exhibited high OD and lethality, further analysis was not undertaken. The second peak (between 90-110 ml) eluates exhibited very low OD and were non-lethal. On bioassay, the 5-HT content of pooled eluates of second peak was $0.0398 \pm 0.008$ $\mu \mathrm{g} / \mathrm{ml}$ and by fluorimetric assay it was $0.0396 \pm 0.007 \mu \mathrm{g} / \mathrm{ml}$. The 5 -HT concentration of crude $M B T$ venom per unit mass was $0.0175 \pm 0.0035 \mu \mathrm{g} / \mathrm{mg}$ by bioassay and $0.0174 \pm 0.0031 \mu \mathrm{g} / \mathrm{mg}$ by fluorimetric assay. Further, the gastric fundus contractions elicited by second peak eluates were blocked by methysergide $(1.0 \mu \mathrm{M})$. Thus, the second peak eluates of crude $M B T$ venom contain 5-HT and its concentration was about $0.0174 \mu \mathrm{g} / \mathrm{mg}$.
\end{abstract}

Keywords: Serotonin, 5-HT assay, Mesobuthus tamulus venom, gastric fundus contractions.

\section{INTRODUCTION}

The Indian red scorpion (Mesobuthus tamulus; MBT) is a lethal species of scorpions in the Indian subcontinent [1]. Envenomation with crude $M B T$ venom manifests with local pain and edema at the site of sting; gastrointestinal problems such as severe spasmodic abdominal pain, abdominal distention, acute pancreatitis, etc.; hematological problems like coagulation defects; cardiovascular problems like tachycardia, arrhythmias, hypertension, myocarditis and ischemialike changes, circulatory failure, etc.; these symptoms have been observed in experimental animals as well as in human beings. Thus, MBT envenomation is lethal with multisystemic involvement [1-4]. Reports elsewhere suggest the role of massive release of neurotransmitters such as catecholamines causing autonomic storm responsible for variety of manifestations [2], but many of the multi-systemic manifestations remain unexplained. Some of the above manifestations can be produced by 5-hydroxytryptamine [5]. 5Hydroxytryptamine (5-HT) has been shown to be present in the venom of Leirus quinquestriatus [6], Lychas laevifrons, Pock [7] and Tityus serrulatus [8] but not in the venom of Indian red scorpion. Therefore, the present study was undertaken to identify and isolate 5-HT in crude $M B T$ venom.

*Address correspondence to this author at the Department of Physiology, Institute of Medical Sciences, Banaras Hindu University, Varanasi - 221005, India; Tel: +91-542-369069/2309551; Fax : +91-542-2367568;

E-mail: desh48@yahoo.com

\section{MATERIALS AND METHODOLOGY}

The experiments were performed as per the guidelines of the Ethical committee (for animal experimentation) of the Institute of Medical Sciences, Banaras Hindu University, Varanasi, India.

\section{Drugs and Chemicals}

Freeze-dried crude Mesobuthus tamulus venom was obtained from Haffkine Institute, Mumbai, India. The Sephadex G 75-125 and 5-HT were obtained from Sigma Chemicals Co., St. Louis, MO, U.S.A. Methysergide was bought from Sandoz, New Jersey, U.S.A. The stock solutions of 5 -HT $\left(10^{-2} \mathrm{M}\right)$ and methysergide $\left(5 \times 10^{-3} \mathrm{M}\right)$ were prepared in distilled water and stored in a freezer. Subsequent dilutions were made with Tyrode solution at the time of experimentation. The composition of Tyrode solution (mM) was $\mathrm{NaCl} 137 ; \mathrm{KCl} 3.7 ; \mathrm{MgCl}_{2} 0.05 ; \mathrm{CaCl}_{2} 1.02$; $\mathrm{NaH}_{2} \mathrm{PO}_{4}$ 0.32; $\mathrm{NaHCO}_{3} 11.9$ and glucose 5.0. All other chemicals used in the study were of analytical grade.

\section{Fluorimetric Assay}

The 5-HT content of the crude $M B T$ venom was determined fluorimetrically using the method described elsewhere [9]. Briefly, $1 \mathrm{ml}$ crude $M B T$ venom $(1 \mathrm{mg} / \mathrm{ml})$ or Sephadex pooled eluate $(1 \mathrm{ml})$ was mixed with $\mathrm{NaCl}(1.0 \mathrm{~g})$, borate buffer $(0.3 \mathrm{ml} ; \mathrm{pH} 11)$ and $n$-butanol $(2 \mathrm{ml})$ using vortex mixer and was centrifuged (x $1400 \mathrm{~g}$ ). The supernatant (1 $\mathrm{ml}$ ) was taken in a tube, mixed with $\mathrm{N} / 10 \mathrm{HCl}(0.1 \mathrm{ml})$ and heptane (1.2 ml), and was centrifuged (x $1400 \mathrm{~g})$. Thereafter, 
the aqueous phase $(0.4 \mathrm{ml})$ was transferred to a tube and mixed with $o$-phthaldialdehyde $(0.6 \mathrm{ml} ; 1 \mathrm{mg} / 10 \mathrm{ml}$ of $10 \mathrm{~N}$ $\mathrm{HCl}$ ) solution and kept in a boiling water bath for $10 \mathrm{~min}$. After cooling, the fluorescence was read in a spectrophotofluorometer with the excitation and emission wavelength set at 360 and $470 \mathrm{~nm}$, respectively.

\section{Bioassay}

The bioassay of 5-HT was performed by using gastric fundus strips obtained from female rats of Charles-Foster strain as described earlier [10,11]. The 5-HT content of crude $M B T$ venom/Sephadex gel eluates was determined by computing the fundus contractions as \% of maximal contractions.

The methods for preparation and recording of gastric fundus contractions were followed as described earlier [11]. From each gastric fundus, two longitudinal muscle strips (25 $\mathrm{mm} \times 4 \mathrm{~mm}$ each) were prepared. The fundus strip was mounted vertically in Dale's organ bath (containing $25 \mathrm{ml}$ Tyrode solution at $33 \pm 1{ }^{\circ} \mathrm{C}$ bubbled continuously with 100 $\left.\% \mathrm{O}_{2}\right)$. The Tyrode solution was changed at every $15 \mathrm{~min}$ unless mentioned otherwise.

The gastric fundus muscle strip preparations were kept under initial resting tension of $0.5 \mathrm{~g}$ and were allowed to equilibrate for $30 \mathrm{~min}$ before recording the isometric muscle contractions using force displacement transducer. The contractile response of fundus muscle strip to different concentrations of 5-HT $(0.0007-7.0 \mu \mathrm{g} / \mathrm{ml})$, crude $M B T$ venom $(0.1-6.0 \mu \mathrm{g} / \mathrm{ml})$ and Sephadex gel eluates $(1.0 \mathrm{ml}$ individually or pooled) were recorded. The area under the curve for one min was computed. The response was expressed as \% of the response produced at $0.7 \mu \mathrm{g} / \mathrm{ml}$ of $5-\mathrm{HT}$ as this concentration produced maximal response.

The fundus contractions to different concentrations of 5HT were recorded in a stepwise manner. The tissue was exposed to a given concentration of 5-HT for one min and a minimum of 5 min was allowed between two concentrations (after washing the preceding concentration twice). After 30 min, the tissue was exposed to a concentration of crude venom. Only one concentration of venom was used in a given fundus strip. In separate series of experiments, the fundus contraction to $0.7 \mu \mathrm{g} / \mathrm{ml}$ of 5-HT was recorded before (control) and after $30 \mathrm{~min}$ exposure to methysergide (1.0 $\mu \mathrm{M})$. Subsequently, the preparation was tested for the response to crude $M B T(1.0 \mu \mathrm{g} / \mathrm{ml})$ venom.

\section{Sephadex Gel Column Chromatography}

The Sephadex gel (G 75-125) chromatography was performed using the method described earlier [4]. Briefly, the Sephadex gel chromatographic column $(1.5 \mathrm{~cm}$ diameter, $51 \mathrm{~cm}$ gel height and gel bed volume $90 \mathrm{ml}$ ) was equilibrated with ammonium acetate buffer $(0.1 \mathrm{M}, \mathrm{pH} 8.4)$ at $25 \pm 0.5$ ${ }^{\circ} \mathrm{C}$. Crude $M B T$ venom $50 \mathrm{mg}$ in $1.0 \mathrm{ml}$ of distilled water was loaded onto it. The column was eluated with same buffer using twice the bed volume $(180 \mathrm{ml})$ at a flow rate of $0.3 \mathrm{ml} / \mathrm{min}$ and eluates were collected in fractions of $2 \mathrm{ml}$ each. The eluates were then screened for optical density (OD) at $280 \mathrm{~nm}$ using spectrophotometer (Carl Zeiss, Germany), effect on gastric fundus contractions (chosen randomly) and lethality (chosen randomly). Lethality was determined by subcutaneous injection of $0.1 \mathrm{ml}$ of Sephadex eluates in abdominal region in young rats (30-40 g) of Charles Foster strain as described earlier [4].

\section{Statistical Analysis}

The data are expressed as mean \pm S.E.M. Statistical comparisons of two groups were performed using Student's t-test for paired or unpaired observations wherever applicable. A P value $<0.05$ was considered significant.

\section{RESULTS}

\section{Estimation of 5-HT in Crude $M B T$ Venom}

The 5-HT concentration by fluorimetric assay was $0.17 \pm$ $0.02 \mu \mathrm{g} / \mathrm{mg}$ of crude $M B T$ venom. To estimate 5-HT equivalence of fundus contraction, a concentration response of 5HT was determined. The 5-HT produced a concentrationdependent fundus contractions $(0.0007-7.0 \mu \mathrm{g} / \mathrm{ml} ; \mathrm{n}=6$ at each concentration). It was observed that $0.7 \mu \mathrm{g} / \mathrm{ml}$ of $5-\mathrm{HT}$ elicited maximum response and ten times increase in the concentration of 5-HT did not increase the magnitude (Fig. 1A).

CV produced a concentration-dependent $(0.1-1.0 \mu \mathrm{g} / \mathrm{ml})$ increase in gastric fundus contractions (Fig. 1B). The maximal contractions were seen with $1.0 \mu \mathrm{g} / \mathrm{ml}$ of venom. Increase in the concentration of crude venom did not increase the magnitude of contraction any further. The contractions seen with $1.0 \mu \mathrm{g} / \mathrm{ml}$ of crude venom were about $45 \%$ maximal contractions produced by $5-\mathrm{HT}$ and corresponded to 20 $\mu \mathrm{g}$ of 5-HT per mg of CV. Thus, 5-HT determined by bioassay was 117 times greater than that estimated fluorimetrically.

\section{Methysergide Partially Antagonized the Crude Venom- Induced Contractions}

Crude $M B T(1.0 \mu \mathrm{g} / \mathrm{ml})$ venom-induced contractions were partially blocked $(55 \%)$ by 5 -HT antagonist methysergide $(1.0 \mu \mathrm{M})$ whereas the contractions produced with 0.7 $\mu \mathrm{g} / \mathrm{ml}$ of 5-HT were completely blocked (Fig. 2).

\section{Isolation of 5-HT from Crude MBT Venom by Sephadex Gel Chromatography}

Sephadex gel column chromatographic eluates exhibited two peaks of gastric fundus contractions. The first peak was observed between $26-70 \mathrm{ml}$ and the second peak was between $90-110 \mathrm{ml}$ of eluate volumes (Fig. 3B). The eluates of first peak exhibited lethality and high OD (Fig 3A, C), and hence were not considered further.

\section{DISCUSSION}

The results of this study demonstrate the presence of 5HT in crude $M B T$ venom. The concentration of 5-HT after performing the chromatographic purification was similar by both the fluorimetric assay and bioassay methods. Further, the gastric fundus contractions induced by bioassay methods from chromatographic eluates were completely blocked by the 5-HT antagonist methysergide.

The 5-HT concentrations estimated from crude $M B T$ venom exhibited a great disparity (117 times) in results between fluorimetric assay and bioassay methods (Fig. 1). Further, methysergide $(1.0 \mu \mathrm{M})$ partially blocked $(55 \%)$ the crude venom - induced gastric fundus contractions (Fig. 2), 


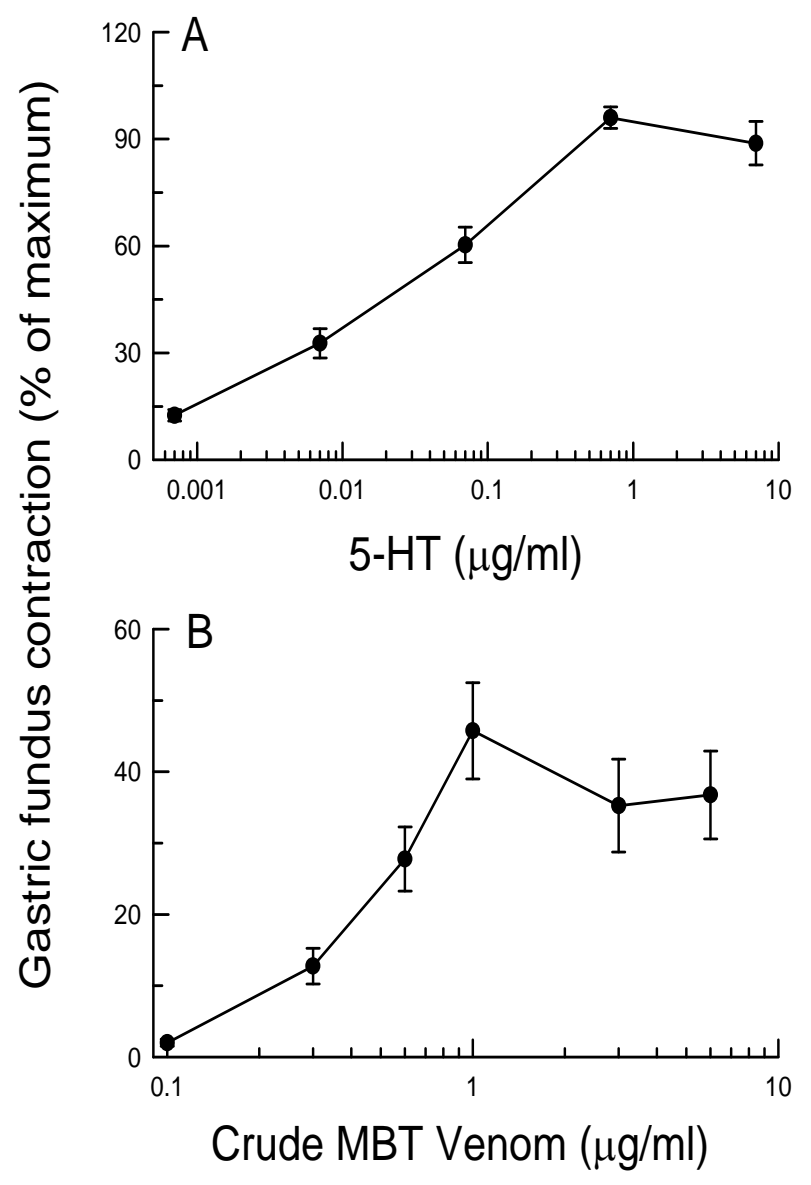

Fig. (1). Determination of 5- HT in crude $M B T$ venom by bioassay method using gastric fundus contractions. The graph in upper panel (A) depicts 5- HT concentration-response on gastric fundus contractions $(\mathrm{n}=6)$. The maximum contraction was observed at 0.7 $\mu \mathrm{g} / \mathrm{ml}$. The graph in lower panel (B) demonstrates concentrationresponse of crude $M B T$ venom on gastric fundus contractions $(\mathrm{n}=6)$. The maximum contraction was produced by $1.0 \mu \mathrm{g} / \mathrm{ml}$ of crude venom.

indicating the presence of other substances such as histamine, kinins, polypeptides and toxins [7, 12], that induce contractions in this biological system. Even the fluorimetric assay may also give higher values as the peptides and polypeptides present in the crude $M B T$ venom also contribute to the fluorescence [13]. Under such circumstances, bioassay and fluorimetric assay methods can not provide exact concentration of 5-HT. Therefore, separation and exclusion of the substances responsible for false high value were necessary to determine the actual concentration of 5-HT in crude $M B T$ venom.

The two peaks of enhanced gastric fundus contractions were observed between $26-70 \mathrm{ml}$ and $90-110 \mathrm{ml}$ of eluate volumes of Sephadex gel column chromatography (Fig. 3B). The eluates of first peak corresponded to higher OD indicating presence of peptides/proteins (Fig. 3B, C). Further, the first peak eluates also exhibited lethality (Fig. 3A). Therefore, increased fundus contractions observed with these eluates may be attributed to the presence of lethal peptide / protein toxins present in the venom [4].

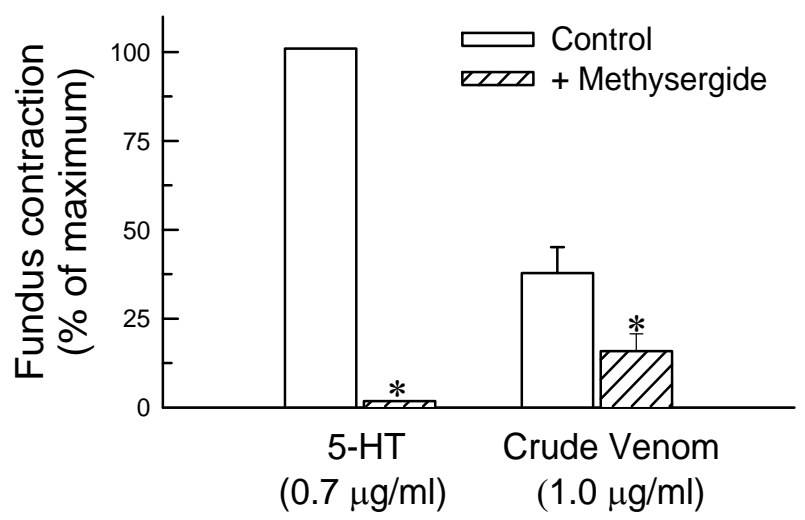

Fig. (2). Methysergide $(1.0 \mu \mathrm{M})$ partially blocked the crude $M B T$ venom-induced gastric fundus contractions. 5-HT response was obtained before and after exposure to methysergide. In another group, the fundus strips were exposed to venom either alone (control) or after pretreatment with methysergide (+ methysergide). The responses were normalized to maximum 5 -HT response obtained initially. An asterisk (*) indicates $\mathrm{P}<0.05$ as compared to control.
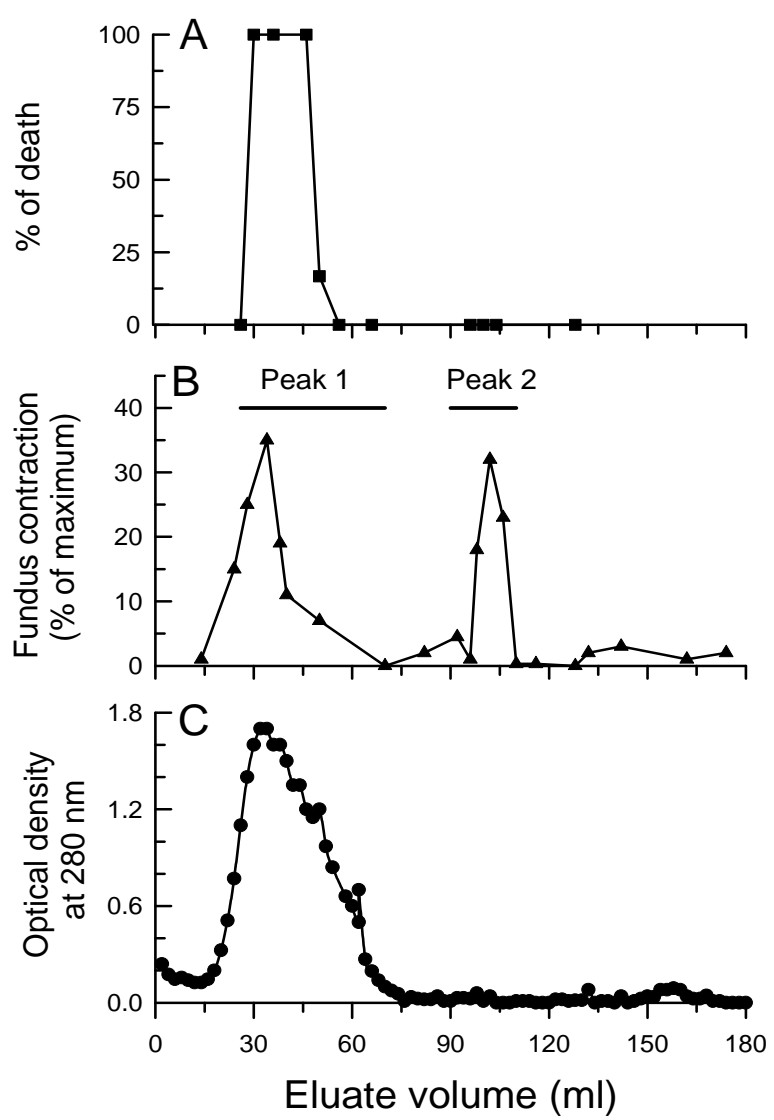

Fig. (3). Isolation of 5-HT from $M B T$ venom using Sephadex gel chromatography. The panel (A) shows lethality of Sephadex eluates as $\%$ of death after subcutaneous injection of $0.1 \mathrm{ml}$ of the eluted fractions screened randomly in six rats. The panel (B) depicts rat gastric fundus contractions as \% of maximum. Two peaks of enhanced gastric fundus contractions were observed. The panel $(\mathbf{C})$ shows optical density (OD) of the eluates at $280 \mathrm{~nm}$. Note that, the first peak $(26-70 \mathrm{ml})$ eluates demonstrated high OD and lethality whereas the second peak eluates (90-110 ml) had low OD and were non-lethal. 


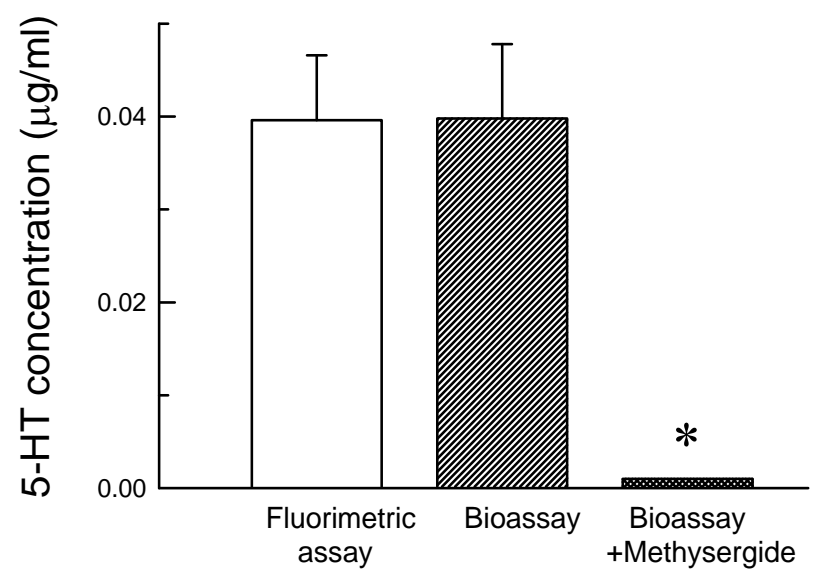

Fig. (4). 5-HT concentration of second peak of Sephadex eluates $(90-110 \mathrm{ml})$ by fluorimetric assay and bioassay methods. The fundus contractions produced by pooled eluates of second peak were completely blocked by methysergide $(1.0 \mu \mathrm{M})$.

The estimated values of 5-HT in second peak eluates observed in this study by bioassay and by fluorimetric assay methods were similar (Fig. 4) indicating that both methods provided comparable results. Previously it is shown that the fluorimetric assay is $90-100 \%$ accurate for the estimation of low concentration of 5-HT [9]. Further, the gastric fundus contractions produced by the pooled eluates of second peak were totally antagonized by methysergide (Fig. 4) and can be attributed to the presence of 5-HT. These values also correspond to the values of 5-HT reported in Leirus quinquestriatus, Lychas laevifrons (Pock) and Tityus serrulatus, respectively [6-8].

It is reported that chemical constituents of scorpion venoms differ from genus to genus and species to species [14, 15]. Till date, venoms from only three species of scorpions as mentioned above contain 5-HT [6-8]. The present study provides the evidence for existence of 5-HT in the venom of the Indian red scorpion. Thus, indicates its role in pathophysiology of scorpion envenomation and explains the systemic changes such as coagulation disorders, abnormality in platelet function, hypertension, etc. associated with $M B T$ envenomation $[2,3]$. This information will help researchers to initiate and plan the investigations to determine the extent of serotonergic involvement in $M B T$ envenomed animals and in human beings.

However, it is pertinent to mention that 5-HT assay performed directly by either method in crude venom of scorpions may provide false high values. The assay method should be applied only in purified fractions to obtain the exact con- centration of 5-HT. Further, it may be better to cross check by other methods.

\section{CONCLUSIONS}

Results of this study revealed the presence of 5-HT in crude $M B T$ venom and the concentration was $0.0174 \mu \mathrm{g} / \mathrm{mg}$. The 5-HT assay needs to be performed on the purified fractions.

\section{REFERENCES}

[1] Tiwari AK, Deshpande SB. Toxicity of scorpion (Buthus tamulus) venom in mammals is influenced by the age and species. Toxicon 1993; 31: 1619-22.

[2] Murthy KRK, Yeolekar ME. Electrocardiographic changes in acute myocarditis produced by scorpion (Buthus tamulus) venom. Ind Heart J 1986; 38: 206-10.

[3] Murthy KRK, Hossein Z, Medh JD, et al. Disseminated intravascular coagulation and disturbances in carbohydrate and fat metabolism in acute myocarditis produced by Indian red scorpion (Buthus tamulus) venom. Ind J Med Res 1988; 87: 318-25.

[4] Deshpande SB, Alex AB, Jagannadham MV, Rao GRK, Tiwari AK. Identification of a novel pulmonary oedema producing toxin from Indian red scorpion (Mesobuthus tamulus) venom. Toxicon 2005; 45: 735-43.

[5] Sanders-Bush E, Mayer SE. In: Hardman JG, Limbird LE, Perry B, Molinoff PB, Ruddon RW, Gilman GA, Eds. Goodman \& Gilman's The Pharmacological Basis of Therapeutics, 9th ed. McGraw Hill Companies 1996; 249-63.

[6] Adam KR, Weiss C. The occurrence of 5-hydroxytryptamine in scorpion venom. J Exp Biol 1958; 35: 39-42.

[7] Basu A, Gomes A, Gomes A, Dasgupta SC, Lahiri SC. Histamine, 5-HT and Hyaluronidase in the venom of the scorpion Lychas laevifrons (Pock). Ind J Med Res 1990; 92: 371-3.

[8] Nascimento EB Jr, Costa KA, Bertollo CM, et al. Pharmacological investigation of nociceptive response and edema induced by scorpion Tityus serrulatus. Toxicon 2005; 45: 585-93.

[9] Jacobowitz DM, Richardson JS. Method for the rapid determination of norepinephrine, dopamine and serotonin in the same brain region. Pharmacol Biochem Behav 1978; 8: 515-9.

[10] Kitchen L. Textbook of In vitro Practical Pharmacology. Oxford, Blackwell Scientific Publications 1984; Chapter 5: 55.

[11] Deshpande SB. Potentiation of serotonin-induced contractility of gastric fundus strips in lactating rats. Acta Physiol Scandinavia 1993; 149: 51-7.

[12] Galvez A, Gimenez-Gallego G, Reuben JP, et al. Purification and characterization of a unique, potent peptidyl probe for the high conductance calcium-activated potassium channel from venom of the scorpion Buthus tamulus. J Biol Chem 1990; 285: 11083-90.

[13] Shalabi A, Zamudio F, Wu X, Andeau SA, Possani LD, Villereal M. Tetrapandin, a new class of scorpion toxins that specifically inhibit store-operated calcium entry in human embryonic kidney-293 cells. J Biol Chem 2004; 279: 1040-9.

[14] Bettini S. In: Erdos EG, Ed. Scorpion venoms in: Handbook of experimental pharmacology, Heidelberg, Springer-Verlag 1978; 25: 459 .

[15] Zlotkin E, Miranda F, Rochat H. In: Bettini S, Ed. Arthropod venoms. Berlin, Springer-Verlag 1978; 48: 317-69. 